\title{
Water Leakage Detection System Using Arduino
}

\author{
Juma S. Tina, Beatrice B. Kateule, and Godfrey W. Luwemba
}

\section{ABSTRACT}

Clean water is a scarce resource for the human life and is subject to wastage due to leakage of the distribution pipes in large cities. Water pipe leakage is a big problem around the world of which most of the water distribution authorities faces difficulties to detect the location of the fault. This problem of leakage can be caused by several factors such as breakage of the pipelines due to aging or ongoing constructions in urban cities like Dar es salaam, consequently due to that case, the distribution authorities face hardship to identify the cause and enable them to take action. Therefore, the aim of this project was to develop an IoT-based system for water leakage detection. The prototype was developed comprising two sensors embedded at the source and destination points to measure the flow rate of water. The result indicated that the volume of water generated at the start point can be compared with the other end to determine if there is any leakage. A greater focus on distance calculation could produce interesting findings that account for more research on IoT monitoring systems.

Keywords: Arduino uno, internet of things, leak detection, NodeMCU esp8266, water flow sensor.

\author{
Published Online: January 3, 2022 \\ ISSN: $2736-5492$ \\ DOI : 10.24018/ejcompute.2022.2.1.43 \\ J. S. Tina \\ Department of Computer Systems and \\ Mathematics, Ardhi University, \\ Tanzania. \\ (e-mail: jusatitinna67@gmail.com) \\ B. B. Kateule \\ Department of Computer Systems and \\ Mathematics, Ardhi University, \\ Tanzania. \\ (e-mail: beatrice.kateule@gmail.com) \\ G. W. Luwemba* \\ Department of Computer Systems and \\ Mathematics, Ardhi University, \\ Tanzania. \\ (e-mail: luwembag@gmail.com) \\ *Corresponding Author
}

\section{INTRODUCTION}

The Internet of Things (IoT) is a major area of interest within the field of data communications and with the advancement of data communication technologies, the number of interconnected devices has increased drastically. The IoT plays a significant role to connect not only humans but electronic devices which speak amongst themselves [1]. The IoT has been instrumental in connecting several electronic devices over a network and then collecting the data from remotely located devices such as sensors which can be distributed in any location. The collected data can be uploaded to any cloud service and thereafter analyzed and processed. The processed information can be used to provide alerts to people by using various means including emails, SMS, buzzer, etc. More recently, there has been an increasing interest in the use of IoT devices to monitor and control parameters in various domains such as weather, home automation, agriculture, energy, health, water distribution, etc. Water is an indispensable element consumed by every organism and therefore the need for offering a good and safe water delivery system is paramount. Moreover, the environment in some locations is not suitable to allow delivery of safe and good water systems. Depending on the terrain, the water pipe network extends underground or over the surface [2]. Wastage of water has become one of the main issues in Tanzania which is greatly attributed to the leakage in the pipes and due to lack of proper system, the leakage goes undetected by the responsible personnel. Currently, the water distribution in an urban area is approximately $73 \%$ compared to rural areas where the distribution is approximately $53 \%$ [3]. For large cities like Dar es Salaam with a population of approximately about 4.3 million [4],[5] the network is spread across the entire city, and there is no mechanism of detecting or monitoring the entire network for detected wastage of water. The problem is not the size of the leak, but what time can be used it takes to detect it. The proposed system is based on IoT with the water flow sensors integrated with Arduino to detect the leakage of water in pipelines and provide an alert on the leaks to the distribution authorities to 2 prevent the loss of water flowing through the pipelines from the distribution centers to the consumers. So due to that, it helps most of the companies like Dar es Salaam Water Supply Company (DAWASCO) to know where there is a leak of the pipe at a certain geographical location where the flow meter sensors are installed and can be displayed on an LCD screen (Liquid Crystal Displays).

\section{LITERATURE REVIEW}

The project of Water Leakage System using IoT was done by [6] in which the system can detect and control the level of water in a certain water tank. Also, to detect the leakage of the pipeline by the alert system and to confirm this through the experimentation using the SIM900 GSM shield, Arduino Mega 2560, and the Geophone sensor that is set up at the edge of the pipe which is generally connected to the circuit. The sensor used in the project is the Geophone sensor and the flow meter which is different from the water flow sensor YF-S201 delete used in my project. Another project was based on the 
Smart Pipeline Water Leakage Detection System by [7] in which the leakage of water can be detected by the flow rate sensors and the water flow can be obstructed by solenoid valves installed in various locations of the pipeline until the faulty component of the pipeline is fixed. The Hall Effect is utilized in the water flow sensor to determine the flow rate of a liquid. The water flow sensor can detect up to $30 \mathrm{~L} / \mathrm{min}$ and a pressure of 2.0Mpa. The IoT solution employs an 8-bit microcontroller, ATmega328 (RISC), with a low power system for operation.

The work by [8] proposed a water leakage detection system with SMS alert using the Node MCU, Water Flow Sensor, Ultrasonic Sensor, and Buzzer. In this project when the leak has occurred, the time taken by the system to deliver the SMS is reliant on the coverage area or range of the specified mobile network. In our project, we use the LCD screen to display the outputs immediately when the pipe leak.

Another project was based on leakage detection using a flow liquid meter sensor by [9] whereby, they use an Arduino chip-based ATmega328P as a microcontroller and a flow liquid meter sensor to monitor the rate of water flow in a pipe with a maximum length of 2 meters, and when the leakage of the pipeline leakage has occurred it can detect but LCD doesn't show the location of the leak. Furthermore, the data cannot be stored on a server.

The work done by [1] proposed a sensor-based leakage detection system in which the user can be notified of the level of water through the mobile application. Also, the system can measure the quality of water if it is less than or more than normal values then the notification is sent to the user as SMS. Leak detection takes place by using the water flow sensor which detects the flow of water. In this project, the hardware requirement is used as an ultrasonic sensor, mobile calling and SMS, water flow sensor, and $\mathrm{pH}$ sensor. In our project we use the LCD screen display to show the output of the readings in the sensors that have been installed in the pipeline to detect if there is a leak, also, to show the position or location of the leakage in a pipeline [9].

\section{Methodology}

A methodology is a set of step-by-step methods for creating a product. There are several software development methodologies such as waterfall methodology, agile methodology, and so on. A software development methodology also can be defined as "the formalized process for handling large projects where documentation, training, integrity, and security are vital to the project's success". SDLC projects naturally use object-oriented analysis and design [10]. The selected software development methodology used was the Agile model. Agile methods and constant delivery are most well suited for dealing with the demands of the connected device. With Agile, the testing suits an important element of each stage of the development process at each stage. Agile methodology is chosen because at every stage of this project testing becomes an important element of each stage of the development process since it involves the devices that were connected with the microcontroller and to produce output according to the system of that project (Water Pipe Leakage Detection System). Also, it helps when there is a change in the requirements, technology, or tools that are used in the project so due to that it makes it easy to adjust your approach to target high-priority issues. The agile model mostly is used in the development of the IoT project. While there is an advantage of using the Waterfall model, but Agile is a very crucial important software development method in the IoT project.

\section{DESIGN AND DEVELopMENT}

\section{A. System Architecture}

Architectural diagram refers to the conceptual model that defines the structure and behavior of a system. An architecture diagram is used to show the relationships, constraints, and boundaries between components. A system architecture consists of the sensing subsystem and the system components to be developed, that will work together to implement the overall system. An architecture diagram displayed in Fig. 1 consists of three parts that perform coherent functions, first is the sensing subsystem that includes all the processes of detecting the water leakage and sending data process. The second subpart is the internet part in which the data is passed from the sensing subpart into a cloud (database server) subpart which is the more reliable storage location, later the user receives the data about the detection of the water leakage through the LCD screen display or the web-based system.

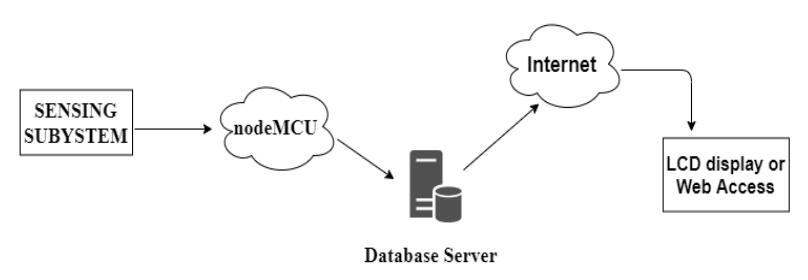

Fig. 1. System architecture.

\section{B. Working Flow Diagram}

Flow chart diagram refers to the diagram that represents the workflow/process of the system. This project is based on an IoT system of detecting the leakage of water, the flowchart shows how the leakage is detected using a sensor placed at both ends. Fig. 2 depicts the flow chart of the proposed system.

\section{Proposed System}

This section provides the interaction between the hardware and software for each subsystem. It involves the interaction of the Arduino board, water flow sensor, nodeMCU, and Arduino IDE. Arduino microcontroller arranged well wood material together with the breadboard, these components are programmed with Arduino IDE in a computer. Also, the water flow sensor and nodeMCU are programmed in the Arduino IDE to measure the readings of water (into liters) as well as sending data to the cloud (database server) and administrator respectively. Fig. 3 shows the component diagram of the water pipe leak detection system. 


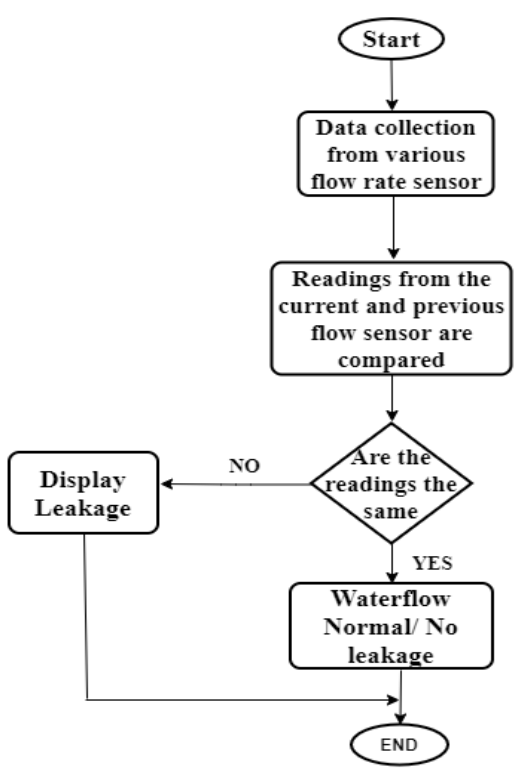

Fig. 1.Flow diagram of proposed system.

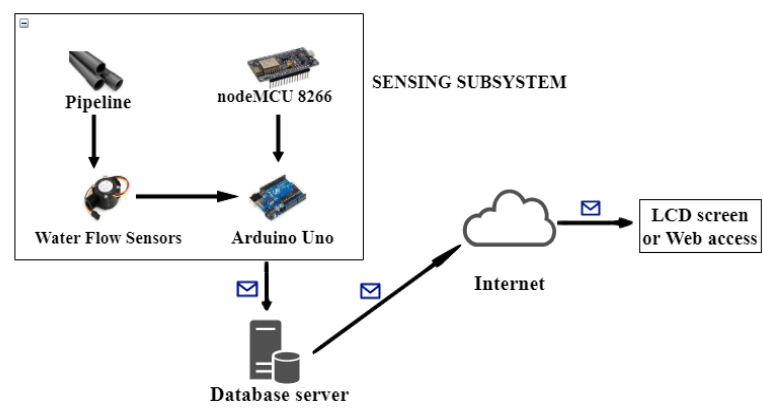

Fig. 3. Design of the proposed system.

The specifications of all the main components used in the proposed system are indicated in Table I. These include the specifications of sensors, microcontroller, LCD screen, and pipes.

TABLE I: REQUIREMENT SPECIFICATIONS

\begin{tabular}{|c|c|}
\hline Hardware & Specifications \\
\hline Water Flow Sensor & $\begin{array}{l}\text { Working Flow Rate: The flow sensor can } \\
\text { detect up to } 30 \mathrm{~L} / \mathrm{Min} \text { and pressure of } 2.0 \mathrm{MPa} \text {. }\end{array}$ \\
\hline $\begin{array}{l}\text { Microcontroller } \\
\text { (Arduino Uno) }\end{array}$ & The input voltage used is about 6 up to $20 \mathrm{~V}$. \\
\hline LCD screen display & $\begin{array}{l}\text { The operating voltage of the LCD is } 4.7 \mathrm{~V} \text { up } \\
\text { to } 5 \mathrm{~V} \text {. }\end{array}$ \\
\hline Water pipe & $\begin{array}{l}\text { Polyvinyl plastic pipe (PVC); pressure-rated } \\
\text { pipe is AWWA C } 900 \text { and ASTM D } 2241 .\end{array}$ \\
\hline
\end{tabular}

\section{PRoJect DESCRIPTION}

\section{A. Device Prototype}

The sensing subsystem is responsible for the detection of the leakage of water pipelines by comparing the amount of water passed through the water flow sensor and Arduino process. The sensing subsystem is enabled to send the data about the leakage of a pipeline directly to the cloud for storage using nodeMCU. This subsystem consists of Arduino Uno, water flow sensor, and nodeMCU, as presented in Fig. 4 The sensing subsystem, is also coupled with a server which is a cloud server that stores data and resends to the intended system of the organization, which receives the data through web access.

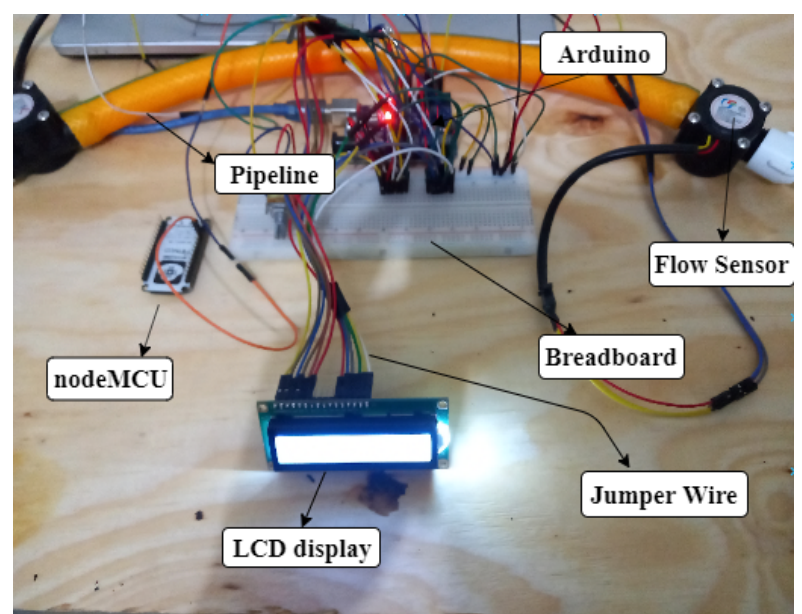

Fig. 4. Sensing subsystem.

Fig. 5 shows the complete prototype of the device, with a sensor connected to the Arduino board which is attached to the breadboard. There is also an LCD screen display that is used to display the output of the water readings and send it to the cloud for future use using nodeMCU which is connected to the breadboard.

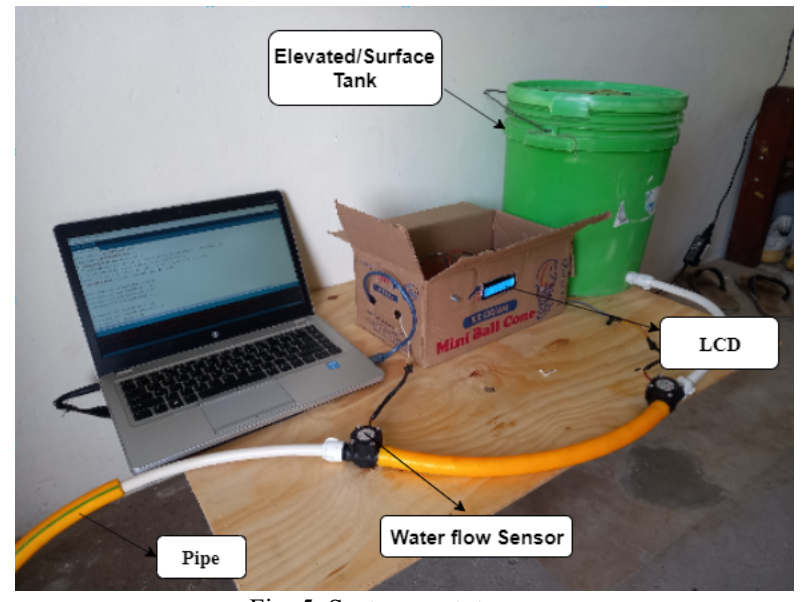

Fig. 5. System prototype

\section{Discussion OF THE RESUlts}

Fig. 6 shows the real-time reading from the sensor places at both ends with each having a capacity of detecting up to $30 \mathrm{~L} / \mathrm{Min}$ and pressure of 2.0 MPa. In this part of the system testing and validation of the prototype were done by detecting the leakage of water in a pipe and the testing was done to replicate the real scenarios. The volume of the water passed through the source and destination sensors were compared to determine the presence of leakage or an overflow of water in a system. When the comparison of the results indicates no difference in reading signifies that there is no leakage in a system. Furthermore, the finding revealed that when the flow rate from the source exceeded the sensor capacity, then an overflow occurred at the destination sensor. An important conclusion drawn from this work is that employing an IoTbased water leakage detection system offers the efficient and proper utilization of this scarce resource for human life. 


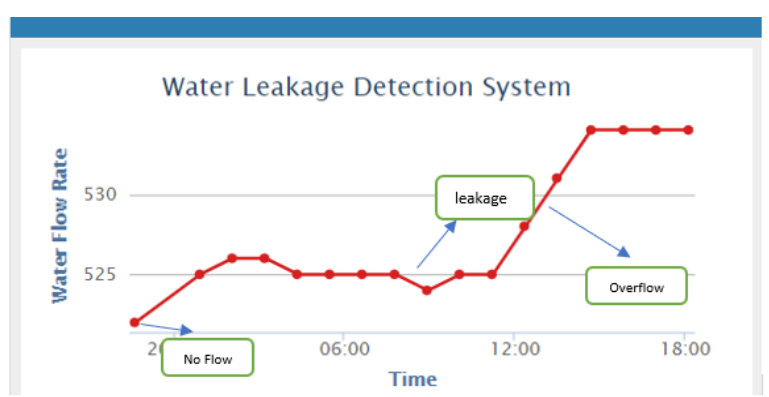

Fig. 6. Graphical representation of the water leakage detection system.

In summary, the current work was completed through the implementation and testing of a water leakage detection system using Arduino. The testing of the prototype was done in a real environment comprising of water distribution sources and destination tanks embedded with a sensing unit. The results of the sensing subsystem are no flow, leakage, and overflow.

\section{CONCLUSION}

This project was undertaken to design a water leakage detection system using IoT. The prototype method was adopted whereby two sensors were placed at each end of the pipe. The study has found that water flowing from the source to the destination can be measured to determine if there is any leak during distribution. Considerably more work will need to be done to determine the exact location where the pipe leaks to assist water distribution authorities to manage this scarce resource properly. A greater focus on distance calculation could produce interesting findings that account for more research on IoT monitoring systems.

\section{REFERENCES}

[1] Dixit PR, Chaudhari H, Jadhav S, Jagtap K. Water Level and Leakage Detection System with its Quality Analysis based on Sensor for Home Application. Int J Innov Res Sci Eng Technol. 2017; 0072(5): 1721-4.

[2] Schindhya, R, Simi, V.P, Sathya, E, Janani, B. Real-Time Water Monitoring System using IoT. Int J Advanced Research in Computer and Communication Eng. 2017; 6(3): 378-380.

[3] Marobhe NJ. A critical review of water supply services in urban and rural areas of Tanzania. Water policy. $2008 \mathrm{Feb}$;10(1):57-71.

[4] National Bureau of Statistics. The 2012 Population and Housing Census: Ministry of Finance, Tanzania, 2013.

[5] Nganyanyuka K, Martinez J, Wesselink A, Lungo JH, Georgiadou Y. Accessing water services in Dar es Salaam: Are we counting what counts?. Habitat International. 2014; 44: 358-66.

[6] Saraswathi V. Water Leakage System Using IoT. Int J Innov Res Eng Manag. 2018; 5(2): 67-9.

[7] Suriya JV. Smart Pipeline Water Leakage Detection System. Int J Appl Eng Res. 2017; 12(16): 5559-64.

[8] Vijayakumar T, Ramachandran T, Vigneshkumar M, Mohananthini N, Saravanan S. Home Water Leakage Detection and Monitoring System Using IOT. J Netw Commun Emerg Technol. 2019; 9(4): 5-10.

[9] Kane SN, Mishra A, Dutta AK. Preface: International Conference on Recent Trends in Physics (ICRTP 2016). J Phys Conf Ser. 2016; 755(1).

[10] Gehman M. Software Development Methodologies. Proj Manag Large Software-Intensive Syst. 2019: 49-66. 